\title{
Effects of addition of water-filled bladders or volatile fatty acids into the rumen on digesta passage in the dairy cow eating ad libitum
}

\author{
JL Peyraud, BP Widyobroto, P Faverdin
}

INRA, station de recherches sur la Vache laitière, 35590 Saint-Gilles, France

The effects of 2 satiation tests on feed intake pattern (Faverdin et al, 1992) and on digesta passage (this trial) were studied.

Four rumen-fistulated cows in mid-lactation (27 kg milk) were successively assigned to 3 treatments: control, VFA infusion and insertion of a 20-I water-filled bladder (WFB) in the rumen. Each period lasted for $14 \mathrm{~d}$. A pelleted diet $60 \%$ dehydrated maize, $30 \%$ concentrate, $10 \%$ hay) was offered ad libitum once daily. Rumen liquid turnover rate (KI) and volume (vol) were estimated by PEG dilution. Mean retention time (MRT) in the digestive tract of maize particles labelled with Eu was calculated from the quantities $(m)$ of marker excreted in faeces $\left(S m_{i} t_{i} / S m_{i}\right)$. Retention time of small particles in the rumen (RT) was calculated from the descending part of the curve.

VFA infusion significantly reduced DM intake but $\mathrm{OM}$ digestibility (OMD) and passage were not modified (table I). WFB decreased DM intake to the same extent as VFA and affected passage. MRT was reduced (table I) as RT decreased by $6 \mathrm{~h}$; vol was slightly reduced $(P<0.15)$ and therefore total rumen volume ( $\mathrm{vol}+W F B$ ) was increased with WFB. OMD (0.69) and $\mathrm{KI}(14 \% / \mathrm{h})$ were not affected. There were large between-cow variations in response to WFB. The extent of MRT (dMRT) and DM intake (dDM) reductions with WFB were related to the initial MRT: the higher the MRT, the larger the dMRT (dMRT = 18.5-0.58 MRT, $r=0.97)$ and the lower $\mathrm{dDMI}$ (dDMI $=-6.7+0.12 \mathrm{MRT}, r=0.98$, $n=4$ ). Thus cows with a high MRT might compensate for WFB, whereas cows with a low MRT might not (cow A vs cow B, table I). The pattern of feed intake was related to digestion. Cow B completed a larger first meal (17.0 vs $7.2 \mathrm{~kg}$ ) with a faster intake rate than cow $A$; this amplified the rumen $\mathrm{pH}$ variations during the meal $(-1.5$ vs -0.8 ) which in turn reduced the rate of in sacco DM degradation (57 vs $73 \%$ degraded in $16 \mathrm{~h}$ ). Nonetheless, DOM was in fact similar for the 2 cows because RT was higher in cow B (32 vs $19 \mathrm{~h}$ ). In conclusion, WFB reduced DM intake presumably as a consequence of insufficient variations in vol or MRT; however, responses varied greatly according to the cow.

Faverdin P, Aubert T, Peyraud JL, Widyobroto BP (1992) Ann Zootech (this issue)

Table I. Effect of treatments on intake and on passage and values for 2 cows (WFB effect in brackets).

\begin{tabular}{llllll}
\hline & Control & VFA & WFB & Cow $A$ & Cow B \\
\hline DM intake $(\mathrm{kg} / \mathrm{d})$ & $21.0^{\mathrm{a}}$ & $19.4^{\mathrm{b}}$ & $19.0^{\circ}$ & $20.5(-2.9)$ & $21.2(-0.5)$ \\
Vol (l) & 83 & 73 & 73 & $73(-15)$ & $99(-21)$ \\
TMRT (h) & $43.5^{\mathrm{a}}$ & $41.2^{\mathrm{a}}$ & $37.3^{\mathrm{b}}$ & $34.3(+0.1)$ & $56.2(-13.9)$ \\
\hline
\end{tabular}

\footnotetext{
a.b: Means with different superscripts are significantly different $(P<0.05)$.
} 